Atos de Pesquisa em Educação - ISSN 1809-0354

Blumenau, v. 13, n.3, p.462-486, set./dez. 2018

DOI: http://dx.doi.org/10.7867/1809-0354.2018v13n3p462-486

\title{
IMAGINAÇÃO, RECONHECIMENTO DE SI E O FAZER HUMANO: CONDIÇÕES PARA AGIR NA SOCIEDADE
}

\section{L'IMAGINATION, LA RECONNAISSANCE DE SOI ET L'ACTION HUMAINE: DES CONDITIONS POUR AGIR DANS LA SOCIÉTÉ}

\author{
IMAGINACIÓN, AUTORRECONOCIMIENTO Y QUEHACER HUMANO: \\ CONDICIONES PARA ACTUAR EN LA SOCIEDAD
}

\author{
DIENER, Kareenn Cristina Zanela \\ jdiener@terra.com.br \\ UNIPLAC - Universidade do Planalto Catarinense \\ MACHADO, Ana Maria Netto \\ laborescrita@gmail.com \\ Université International Terre Citoyenne
}

\begin{abstract}
RESUMO Este artigo traz resultados parciais de pesquisa concluída. A dissertação abordou a articulação entre os conceitos de imaginação, criatividade e reconhecimento para compreender as condições para o autodidatismo e para agir na sociedade, consideradas dimensões relevantes na formação. Neste trabalho focamos especialmente a relação entre a imaginação e o fazer humano, a capacidade e agir na sociedade. A pesquisa foi bibliográfica perpassada pelo método fenomenológico hermenêutico, com ênfase em Paul Ricoeur. Os resultados indicaram que imaginação, criatividade e reconhecimento contribuem para o autorreconhecimento e para o ser capaz de ação na sociedade.
\end{abstract}

Palavras-chave: Criatividade. Fenomenologia hermenêutica. Imaginação. Reconhecimento.

RESUMÉ Cet article aporte des résultats partiels d'une recherche conclue. Elle met en relation les concepts d'imagination, créativité e reconnaissance pour compreendre et pousser la capacité d'agir en société, que l'on considère importantes pour la formation humaine. Ce travail a reflexi sur des différents processus qui connectent l'imagination et l'action humaine: être capable d'agir en société. La recherche consiste dans une refléxion théorique, suivit d'aprés la méthode phénomenologique herméuneutique, dans le versant de Paul Ricoeur. Les résultats indiquent que I'imagination, la créativité et la reconnaissance contribuent pour l'autoreconnaissance de soi et pour devenir capable d'action et transformations sociales.

Mots-clés: Créativité. Imagination. Reconnaissance. Phénomenologie herméneutique.

RESUMEN Este artículo presenta resultados parciales de una investigación concluida. La disertación abordó la articulación entre los conceptos de imaginación, creatividad y reconocimiento con vistas a la comprensión de las condiciones del autodidactismo y el actuar en la sociedad, dimensiones entendidas como relevantes en la formación. 


\section{Atos de Pesquisa em Educação - ISSN 1809-0354 \\ Blumenau, v. 13, n.3, p.462-486, set./dez. 2018 \\ DOI: http://dx.doi.org/10.7867/1809-0354.2018v13n3p462-486}

En este trabajo se enfoca especialmente la relación entre la imaginación y el quehacer humano o la capacidad de actuar en la sociedad. Fue una investigación bibliográfica embebida de método fenomenológico hermenéutico, con énfasis en Paul Ricoeur. Los resultados indicaron que la imaginación, la creatividad y el reconocimiento contribuyen al autorreconocimiento y a la capacidad de actuar en la sociedad

Palabras clave: Creatividad. Fenomenología hermenéutica. Imaginación. Autorreconocimiento.

\section{INTRODUÇÃO}

Este artigo tem origem em uma pesquisa de mestrado concluída, que buscou aprofundar a compreensão sobre o autodidatismo, explicitando os processos nele envolvidos. Os resultados que apresentamos neste trabalho deixam em segundo plano a temática principal da dissertação para refletir sobre alguns processos associados à imaginação, ao reconhecimento e, em menor grau, à criatividade, como elos que ligam o conhecimento de si mesmo ao fazer humano. Para tal, enveredamos em uma pesquisa bibliográfica perpassada pela fenomenologia hermenêutica de Paul Ricoeur ${ }^{1}$, entre outros autores também relevantes.

O tema da imaginação, sobretudo no tratamento que lhe é dado por Ricoeur, surgiu em meio às buscas de literatura em torno do autodidata. Mesmo não sendo o foco deste artigo, contextualizar este escrito parece-nos relevante. Queríamos compreender como alguém poderia se tornar um autodidata, que processos levam a essa condição. Um longo caminho que passou, inicialmente, pela exploração de autores cognitivistas que tratavam da inteligência e das pessoas diagnosticadas "com altas habilidades" ou "superdotados", terminou fazendo com que descobríssemos o hermeneuta e suas teorias sobre a imaginação como fundamental para a ação na sociedade. E é este o tema que nos ocupa neste trabalho.

\footnotetext{
1 Paul Ricoeur, nascido em 1913, na França, tornou-se eminente filósofo cujas principais problematizações giram em torno da hermenêutica de si. Também se preocupou com temas abrangentes que versam sobre a linguagem, a vontade, a liberdade, o mal. Suas publicações incluem Filosofia da Vontade (1960), A Metáfora Viva (1975), Tempo e Narrativa (1983-5) e Si mesmo como outro (1990), Percurso do Reconhecimento (2006b), dentre inúmeros livros e textos que deixou até sua morte em 2005" (RAYNOVA, 2014). Segundo Castro (2002), "podemos distinguir três momentos na sua obra: o fenomenológico-antropológico, o hermenêutico e o ético-ontológico. No primeiro há reflexão sobre a hermenêutica dos símbolos, no segundo há a hermenêutica dos textos e em terceiro a hermenêutica da ação (CESAR, 2002).
} 


\section{Atos de Pesquisa em Educação - ISSN 1809-0354 \\ Blumenau, v. 13, n.3, p.462-486, set./dez. 2018 \\ DOI: http://dx.doi.org/10.7867/1809-0354.2018v13n3p462-486}

A obra de Ricoeur é esclarecedora e indicou caminhos para prosseguir. O instigante fator que media a ação começou a mostrar-se associado ao reconhecimento do outro e de "si-mesmo". Poderia, então, a pessoa que se reconhece em suas capacidades se tornar agente de sua ação, por meio de intrincados processos? Quais seriam? Qual envolvimento possível dos professores no percurso do ensino? No caminho de compreender a ligação entre a noção de reconhecimento e outras noções trabalhadas por este autor, este foi adquirindo centralidade na pesquisa, tornando-se importante fonte de estudos.

Ricoeur trata, em diferentes obras, do reconhecimento, que muitas vezes designa com outros termos, como atestação. Também aborda a ipseidade ${ }^{2}$, que liga a ação humana ao reconhecimento de "si-mesmo", a uma ontologia com dimensões sociais, mediadas pela imaginação. Ao trabalharmos estes temas perguntamo-nos: ser sujeito de ação é fruto da intervenção da imaginação?

Diante das possibilidades e também dificuldades de compreensão deste tema, esta pesquisa se revestiu de interesse, tanto para pesquisadores e professores como para a sociedade. Esta pode lançar esclarecimentos sobre como podemos contribuir para que pessoas se tornem protagonistas de suas ideias e ações, o que poderia ter relevância para promover o autodidatismo, o protagonismo e a autonomia, estes dois últimos tantas vezes mencionados como metas educacionais.

Inscrevemos então nossa investigação na fenomenologia hermenêutica, método que envolve permanecer atento aos movimentos do texto e ao que ele vai revelando. Nessa vertente interpretativa, argumentação e diálogo compõem o processo de busca do desvelamento de sentidos do texto.

\section{IMAGINAÇÃO E CRIATIVIDADE: ELEMENTOS PROPULSORES DO AUTODIDATISMO E DA AÇÃO NA SOCIEDADE}

\footnotetext{
2 "Se há um ponto no qual o pensamento dos modernos marca um avanço em relação ao dos gregos, no que diz respeito ao reconhecimento de si, não é principalmente no plano da temática, o do reconhecimento da responsabilidade, mas no plano da consciência reflexiva de si mesmo implicada nesse reconhecimento (RICOEUR, 2006b, p. 105). Ele utiliza 'ipseidade' como equivalente aos vocábulos ingleses self e selfhood [...]"
} 


\section{Atos de Pesquisa em Educação - ISSN 1809-0354 \\ Blumenau, v. 13, n.3, p.462-486, set./dez. 2018 \\ DOI: http://dx.doi.org/10.7867/1809-0354.2018v13n3p462-486}

Inicialmente, exploramos, de maneira breve, o tema da imaginação e criatividade em diversos autores. Em Landau (2002), por exemplo, a imaginação, quando aliada aos processos cognitivos, é agente que constrói a ação. Já para Begué (2003), ela é a ponte entre a possibilidade e a concretude. E para Sternberg (2006), a imaginação se apresenta como um atributo que deve ser desenvolvido.

Há um vínculo indissociável da imaginação com a criatividade e a ação humana sobre o qual Ricoeur (2002) afirma o seguinte: a imaginação ${ }^{4}$, sendo uma percepção anterior ao real, dará a nós o poder do "possível prático", isto é, a imaginação se comporta como uma antecipação a toda ação. Por meio desta antecipação podemos atuar no planejamento do projeto; é por meio dela que nos sentimos motivados e nos adjudicamos poder: o "poder-fazer, poder-atuar". Refere Ricoeur (2002, p. 207): “[...] la imaginación entra en composición con el proceso mismo de la motivación [...] finalmente, en lo imaginario ensayo mi poder de hacer, tomo la medida del yo puedo"s.

Para aprofundar um pouco mais a questão, valemo-nos do pensamento de Immanuel Kant (1996); este considera que a imaginação se apresenta como a faculdade do espírito do qual resulta o gênio. É a imaginação, para Kant, o meio pelo qual se concretiza a síntese do diverso, a que permite ao homem a compreensão e o entendimento dos objetos que estão em seu entorno. Esta reunião do diverso é feita mediante um esquema que os sintetiza, dando sentido às coisas.

$O$ fato da imaginação também estar ligada aos superdotados e aos autodirigidos é um dos motivos pelos quais Sternberg e Davidson (1986), Renzulli (1986), Landau (2002) e Sternberg (2006) situam a criatividade como o principal

\footnotetext{
3 Marie-France Begué é doutora em Filosofia (Universidade de Salvador, Argentina), membro fundador da Associação Argentina de Fenomenologia e Hermenêutica, representante e membro fundador do Círculo Latino Americano de Fenomenologia (CLAFEN); representa também o Fonds Ricœur na América Latina e a Associação International Paul Ricœur. Investigadora da obra do autor produziu inúmeros artigos e livros que contém contribuições valiosas para a compreensão de sua complexa e vasta obra (RICOEUR STUDIES, 2013).

${ }^{4}$ Refere Castro (2002) que os autores que mais influenciaram Ricoeur nas nuanças que foi atribuindo à noção foram Platão, Aristóteles, Descartes, Kant, Husserl e Sartre.
}

5 As autoras decidiram manter as citações em espanhol na língua original, uma vez que este idioma é majoritário na América Latina. Assim, consideram importante o esforço do leitor brasileiro para o fortalecimento da integração com os acadêmicos hispano-americanos. As citações de obras em inglês foram traduzidas livremente incluindo-se a versão do original em nota de rodapé. Algumas obras lidas em versão castelhana já existem em edições brasileiras, mas a escolha por algumas edições em castelhano obedeceu ao critério da facilidade de acesso às obras. 


\section{Atos de Pesquisa em Educação - ISSN 1809-0354 \\ Blumenau, v. 13, n.3, p.462-486, set./dez. 2018 \\ DOI: http://dx.doi.org/10.7867/1809-0354.2018v13n3p462-486}

atributo dos indivíduos talentosos, das pessoas com propensão a serem autodidatas, pois são pessoas que agem, são sujeitos de ação. A criatividade é um atributo da personalidade proativa e favorece assumir um importante papel no funcionamento da ação enquanto qualidade do ousar. Para Sternberg (2006), "[...] esses atributos incluem, mas não são limitados à vontade de superar os obstáculos, à determinação de assumir riscos razoáveis, à disposição para tolerar a ambiguidade e a autoeficácia." (STERNBERG, 2006, p. 89). ${ }^{6}$

A ação pressupõe "correr riscos", aventurar-se faz parte da vida cotidiana, mas nem todos estão dispostos a encará-los. Nesse sentido, arriscar-se denota um traço relevante que distingue algumas pessoas da maioria, que normalmente não arriscaria sua "estabilidade" em busca de algo novo, em busca do possível, quer seja por valores morais, éticos ou de foro íntimo.

É um agir no mundo, uma possibilidade concreta de modificação. Para que se efetue este atuar no mundo, faz-se necessário, segundo Sternberg (2006), a concordância de muitos recursos, além dos atributos próprios da personalidade e do autodomínio, que colaboram neste sentido. Refere Stenberg,

[...] a criatividade exige uma confluência de seis recursos distintos, mas interrelacionados: habilidades intelectuais, conhecimento, estilos de pensamento, personalidade, motivação e ambiente. Embora os níveis desses recursos são fontes de diferenças individuais, muitas vezes, a decisão de usar um recurso é a mais importante fonte das diferenças individuais (STERNBERG, 2006, p. 88). ${ }^{7}$

Aqui vemos que a criatividade reúne uma vasta gama de recursos que, juntos, conformam a personalidade, mas é a decisão, a eleição pessoal que encaminha se de fato a pessoa vai ou não usar este recurso.

Como Sternberg (2006) afirma que a imaginação pode ser incrementada, também conceitua ser importante o papel da escola no desenvolvimento da criatividade pessoal: "[...] se as escolas não valorizam ou desvalorizam a criatividade,

\footnotetext{
${ }^{6}$ Tradução livre de "These attributes include, but are not limited to, willingness to overcome obstacles, willingness to take sensible risks, willingness to tolerate ambiguity, and self-efficacy" (STERNBERG, 2006, p.89).

7 Tradução livre de: "[...] creativity requires a confluence of six distinct but interrelated resources: intellectual abilities, knowledge, styles of thinking, personality, motivation, and environment. Although levels of these resources are sources of individual differences, often the decision to use a resource is a more important source of individual differences" (STERNBERG, 2006, p. 88).
} 


\section{Atos de Pesquisa em Educação - ISSN 1809-0354 \\ Blumenau, v. 13, n.3, p.462-486, set./dez. 2018 \\ DOI: http://dx.doi.org/10.7867/1809-0354.2018v13n3p462-486}

eles tendem a terem maus estudantes [...]"8 (STERNBERG, 2006, p. 89). Por isso, chama a atenção para o fato de a criatividade estar ligada ao aprendizado.

Para Jesus (2013), a escola pode fomentar tarefas desafiadoras que congreguem processos cognitivos com o consequente emprego do conhecimento, em um misto de amparo e liberdade ou, como diz Landau (2002, p.157), "[...] segurança e liberdade [...]." Segurança para ir além dos seus limites em busca do novo, e liberdade para ser ela mesma, com suas potencialidades e limites. Enfim, amparo, segurança e liberdade, dispostos em conjunto, darão à criança a independência de, por si-mesma, de forma autônoma, buscar seus próprios meios para a transformação de seu entorno. É a mescla de desafio e criatividade que pode levar a um aprendizado edificante e humanamente produtivo.

A escola e os diferentes locais de ensino, bem como a sociedade, podem ter a missão de buscar meios de prover o incremento das capacidades e atributos inerentes ao indivíduo, meios que valorizam o humano e contribuem para a construção do ser. É em meio aos processos de liberdade não cerceada que os autodidatas criativoprodutivos conseguem se desenvolver. Para Sternberg (2006, p.255), "[...] a necessidade de autodeterminação ou uma sensação de autonomia é satisfeita quando se é livre para se comportar por sua própria vontade, em vez de ser forçado a se comportar de acordo com os desejos do outro."9

Nestes termos, se tomarmos como base essas teorias, a escola e os locais de ensino podem transformar-se em fomentadores de pensadores criativos, de espírito crítico com potencial de integração, que buscam soluções aos problemas existentes e não apenas se dedicam a armazenar conhecimentos. Para aquele autor, a história é feita por pessoas criativas, por indivíduos que auxiliam na construção do pensamento.

É no conhecimento de suas capacidades, que fatores como motivação, autoafirmação, ajuste, resiliência e autocontrole encontram um solo fértil. O processo

\footnotetext{
${ }^{8}$ Tradução livre de: "If the schools do not value or devalue creativity, they tend to be worse students" (STERNBER, 2006, p .89).

9 Tradução livre de: "The need for self-determination or a sense of autonomy is satisfied when one is free to behave of one's own volition, rather than being forced to behave according to the desires of another" (STERNBERG, 2006, p. 255).
} 


\section{Atos de Pesquisa em Educação - ISSN 1809-0354 \\ Blumenau, v. 13, n.3, p.462-486, set./dez. 2018 \\ DOI: http://dx.doi.org/10.7867/1809-0354.2018v13n3p462-486}

de concepção e produção é em si mesmo um processo criativo, de rearranjo, de alguma maneira associado ao grau de confiança que temos em nós mesmos.

\section{A IMAGINAÇÃO COMO “ABERTURA” E A POÉTICA DO FAZER}

Uma das dimensões relevantes destacadas por Ricoeur (2002) que concorre para o reconhecimento de si como um ser de ação é a presença da imaginação. Embora o entendimento do que seja imaginação e o papel que desempenha nas diferentes vertentes de pensamento apresentadas, bem como a compreensão do autodidatismo, não seja a mesma entre os diversos autores, a maioria destes a considera importante.

O que vem a ser a imaginação? A imaginação é uma dimensão mediadora. É exatamente na imaginação que encontramos o ponto de conexão que liga o conhecimento de "si" com o fazer humano. A imaginação, como é vista por Ricoeur (2002), torna possível o desenvolvimento do ato criativo. Para Begué (2003), é célula inicial a base de toda ação humana. "Esta relación se da mediante los esquemas imaginarios. En efecto, la imaginación anticipatoria del obrar permite que cada uno 'ensaye' los diversos cursos eventuales que puede tomar su acción, con las diversas consecuencias" (BEGUÉ, 2003, p.72).

Encontramos, esmiuçada por Begué (2003), a aproximação da criatividade com o reconhecimento e a ipseidade como parte da constituição do homem. Ricoeur reconhece, no prólogo do livro de Begué (2003), que a autora conseguiu aprofundar a questão da união da imaginação ao ato que faz possível a criação. Vejamos suas palavras a respeito da perspicácia da obra: "[...] el acceso original de Marie-France Begué está en proponer la relectura bajo el signo de las variaciones imaginativas y, por lo tanto, en la órbita de la poética del acto creador [...]" (RICOEUR, apud BEGUÉ, 2003, p. 15). Seus estudos se tornaram valiosos para a compreensão da imaginação como um ato criativo.

La idea original que preside la tesis fue buscar en la imaginación el punto de anclaje del acto poético, al que le está consagrada la primera parte. Si la imaginación puede ser así considerada como la matriz de todos los desarrollos es porque tiene una estructura que hace posible la creación y porque esta estructura, a su vez, desarrolla una temporalidad propia 


\section{Atos de Pesquisa em Educação - ISSN 1809-0354 \\ Blumenau, v. 13, n.3, p.462-486, set./dez. 2018 \\ DOI: http://dx.doi.org/10.7867/1809-0354.2018v13n3p462-486}

proyectada hacia delante de sí misma, por un presente de iniciativa (RICOEUR, apud BEGUÉ, 2003, p. 15).

A imaginação leva em si mesma um elemento de temporalidade que permite projetar o futuro. A ação, a iniciativa que se apresenta no presente, exige que eu me jogue no futuro, em um irmanar-se de presente-futuro, em busca de um desenvolvimento, de um desenrolar que faz possível a criação. Por isso, pessoas pouco imaginativas criariam menos, concretizariam menos. Para Ricoeur (2002),

La imaginación es precisamente lo que todos entendemos: un libre juego con las posibilidades, en un estado de no compromiso con respecto al mundo de la percepción o de la acción. En este estado de no compromiso, ensayamos ideas nuevas, valores nuevos, nuevas maneras de estar en el mundo (RICOUER, 2002, p. 203).

Sendo um livre jogo com as possibilidades, emana algo de futuro, que só existe a priori mentalmente ou na linguagem, mas que ainda não se tornou realidade. Podendo assim, neste ensaio, ficar sempre nesta esfera e nunca ganhar concretude. Ou pode realizar-se, efetivar-se. Mas para que exista este cogitar de possibilidades, Ricoeur (2006b) mostra que precisamos de liberdade, ludicidade, não coação, não ter compromisso com isto ou aquilo, para poder passear na imaginação, sem muitas exigências, sem obrigações, sem regras restritivas, sem um dever ser constrangedor.

Este livre jogo com as possibilidades em seu ensaio com o novo vem a se constituir na própria "poética de la voluntad". Vontade de fazer, de acontecer, de tecer novas tramas, de experimentar. Neste momento, entra em jogo a poética da experimentação, sendo promovida pela capacidade imaginativa, que traz à tona por meio de uma "significação emergente", da emersão do real significado das coisas as inúmeras possibilidades, reconfigurando-as, tramando, tecendo, "brincando", como se fosse um vaivém, uma poética do fazer.

Esta tessitura feita pela imaginação evoca mais e mais imagens, produzindo uma certa ressonância metafórica, um continuum que não se acaba. É dessa forma que o processo do pensar/imaginar pode se converter no pensamento complexo e na capacidade de fazer conexões. A vontade, a partir da imaginação, traz à tona o significado das coisas. Estes significados "puxam" outros, e outros mais, como um 


\section{Atos de Pesquisa em Educação - ISSN 1809-0354 \\ Blumenau, v. 13, n.3, p.462-486, set./dez. 2018 \\ DOI: http://dx.doi.org/10.7867/1809-0354.2018v13n3p462-486}

eco, uma reverberação, uma livre tradução dos pensamentos que propiciam o ato criativo.

Em uma perspectiva fenomenológica seria pouco adequado estabelecer contornos nítidos entre conteúdo interior (psíquico) e influências sociais e culturais, mas é justamente a imaginação que contribui com esse movimento ou fluidez das velhas e novas ideias. Esta reverberação imaginativa é a responsável por esse contínuo entre o que costuma se considerar dentro e fora, em cima e em baixo, possível e impossível, que dotarão o ser de capacidades e potencialidades. Para Ricoeur (2002,p.203), "[...] al esquematizar la atribución metafórica, la imaginación se difunde en todas direcciones, reanima experiencias anteriores, despierta recuerdos dormidos, irriga campos sensoriales adyacentes [...]."

A riqueza metafórica que advém com o intrincado perceptivo é "decodificada" pelo processo imaginativo, permitindo, assim, uma clara compreensão do entendimento do entorno e, logo, transformando-se em imagem/ação.

Segundo Begué (2003), quando pensamos em projeções futuras ou, mais precisamente, quando trabalhamos a aprendizagem, a imaginação - enquanto nascimento do pensamento - abre-se "el reino de los posibles". Ela é provedora da energia necessária para consecução do projeto eleito, por meio de uma motivação antecipatória. Fato suficiente para compreendermos porque a imaginação primária, quando aliada à criatividade, sendo a mesma incentivada, faz do sujeito de promessas um sujeito de ação. É na capacidade de "ver o novo", de reconfigurá-lo por meio de complexos processos cognitivos, que reside a chamada "genialidade" dos grandes feitos. O artista, o criador, o cientista "[...] ve las cosas con cierta ingenuidad, como si las estuviera viendo por primera vez. Siempre está dispuesto a volver a nacer [...]" (LANDAU, 1996, p. 2).

Ao se deparar com algo que lhe interessa, toma-se de assombro, em um misto de curiosidade e ímpeto de conhecimento, esmiuçando para compreender sua totalidade, já alçando voos que, conduzidos por sua imaginação, antecipam o projeto que no futuro transformar-se-á em ato - descobertas, criações, comprovações, por exemplo.

Nesse sentido, a criança poderia ser vista como exemplo de projeto e promessa; inicialmente não reconhece os limites impostos por regras sociais ou por 


\section{Atos de Pesquisa em Educação - ISSN 1809-0354 \\ Blumenau, v. 13, n.3, p.462-486, set./dez. 2018 \\ DOI: http://dx.doi.org/10.7867/1809-0354.2018v13n3p462-486}

pessoas com quem convive e que dela se ocupam, educando-a e incentivando-a. É livre, crê em "si-mesma", tem criatividade e está sempre pronta a tentar algo novo rumo ao desconhecido, assumindo riscos sérios, muitas vezes, por ainda não saber com precisão medir as consequências de seus atos.

Como vimos anteriormente, assumir riscos é uma condição para a imaginação criadora. Por isso, pode ser trabalhada também no processo educativo para que no futuro seja confiante e criativa, para que não perca essa condição que é inerente à infância, mas que, pelas vias da socialização - muito dela acontecendo na escola vai perdendo força, cedendo às regras de convivência social e vida em comum.

A imaginação, como excerto do processo criativo, é então uma peça preponderante nos intricados processos do reconhecimento. Para Begué (2003, p.26), "[...] se trata de describir la imaginación desde adentro, desde las condiciones que la posibilitan y los procesos que la legitiman. [...] se trata de ver los alcances de imaginación como un 'proceso poético' en la edificación del sí-mismo [...]."

É a imaginação um ato que participa da edificação do sujeito, como um processo formativo. Landau (1996, p.2) concebe que a imaginação, quando aliada à ação da cognição, terá como resultado o surgimento da criatividade humana, em uma mescla de processos psíquicos e sociais: "El pensamiento creativo es una actividad bi-polar entre la lógica y la imaginación, [...] un resultado de la comunicación intra e interpersonal [...]."

Mas, afinal, como podemos congregar os diferentes fatores promotores, como a confiança, liberdade e imaginação para a edificação de si mesmo, tendo em vista a autonomia? Na criança, como foi visto antes, podemos conceituar que poderá se dar por meio do "[...] amparo e da liberdade [...]" (JESUS, 2013, p. 50). A criança deveria ser amparada no momento em que acontece a ruptura, a saída do lar. Deveria ser auxiliada, para que pudesse fazer essa passagem de forma suave e benéfica. Este desligamento pode se dar sob a forma de autonomia e confiança. São, pois, a confiança, o amparo, a liberdade e a segurança os agentes de tal desligamento. A segurança de estar sendo amparado, em que pese ter que seguir seu caminho de forma autônoma, confere suavidade ao processo.

Ricoeur atesta que "[...] é a confiança na permanência da solicitude recíproca que faz do desligamento uma provação benéfica" (RICOEUR, 2006a, p. 205). Quando 


\section{Atos de Pesquisa em Educação - ISSN 1809-0354 \\ Blumenau, v. 13, n.3, p.462-486, set./dez. 2018 \\ DOI: http://dx.doi.org/10.7867/1809-0354.2018v13n3p462-486}

são propiciados, por meio da família, dos tutores etc., os meios para que a criança possa adquirir confiança em si mesma, não mais como uma teoria, mas como uma verdade, conduzida pela segurança do "eu posso", são erigidas, qual sólidos fundamentos, as bases para o desenvolvimento de seus potenciais. Uma vez fundamentada a base, dificilmente haverá algo que possa abalar essa certeza.

\subsection{A IMAGINAÇÃO E O RECONHECIMENTO NO PROCESSO FORMATIVO}

A esfera do ensinar e aprender compreende um processo que pode ser feito por meio da mutualidade, como um meio de ajuda mútua, nas relações do dar e receber. O professor poderia se tornar o mediador, a ponte de ligação que conduz o aprendiz à descoberta de seus potenciais, a conhecê-los e a valorizá-los, para poder deles usufruir ao longo da vida. Levar a criança a compreender o benefício das relações implicadas no "si" e no outro, num processo cooperativo para o benefício de todos. Encarar as relações com crianças, considerando que elas são entes de potência e promessa [este é o caso também dos autodidatas, dos diferentes, etc.], passa também por um repensar nos benefícios que a troca pode implicar, pois,

Quizá ahí reside la prueba suprema de la solicitud: que la desigualdad de poder venga a ser compensada por una auténtica reciprocidad en el intercambio, la cual, en la hora de la agonía, se refugia en el murmullo compartido de las voces o en el suave apretón de manos (RICOEUR, 2006a, p. 198).

É um entregar liberto do peso da autoridade, é um compensar as diferenças pela interação na igualdade, na generosidade, na amorosidade de um gesto recíproco. É antes de tudo abstrair-se da noção de que o outro está somente na condição de receber e não de dar. É aceitar o aprendizado retroalimentado em uma relação de mutualidade.

Para Begué (2003, p. 236), "sólo la actitud ético-poética de un amor donante y disponible puede soportar y superar, respetando, la relativa pero legitima autonomía de una libertad 'solamente humana'." Assim é o amor configurado como uma atitude ética, na qual se alia a poética, que pode dar as bases para a autonomia e a liberdade humana. 


\section{Atos de Pesquisa em Educação - ISSN 1809-0354 \\ Blumenau, v. 13, n.3, p.462-486, set./dez. 2018 \\ DOI: http://dx.doi.org/10.7867/1809-0354.2018v13n3p462-486}

E no adulto? De que modo conceitua Ricoeur (2006b) a consecução da ação para se inverter a negação de "si", criada face ao não reconhecimento? $\mathrm{O}$ autor postula que este processo pode se dar por meio do reconhecimento mútuo. Podemos reverter o problema agindo por esta via: o menosprezo suscitado pela indiferença e não estima poderá ser superado pela consideração. E a injustiça, pelo respeito, em um processo que vai "[...] do polo negativo rumo ao polo positivo, do menosprezo rumo à consideração, da injustiça rumo ao respeito [...]" (RICOEUR, 2006b, p. 188), efetuados nas trocas simbólicas do dar e receber sem esperar recompensa.

Reverter a negação de "si-mesmo" é um processo doloroso, gerador de conflitos e angústias. Processo que, visto sob a ótica de Ricoeur (2006a), e também de Sennett (2001), necessita de ações que operem nas esferas íntimas e públicas. $\mathrm{Na}$ esfera íntima em função de "assumir-se e aceitar-se como se é". Um estimar-se acima das debilidades e fraquezas, um reconhecimento de que somos todos capazes. Um sentimento de liberdade atestado na ação. É, em última análise, um conseguir agir de forma emancipada, um algo de certeza que conduza à autonomia. É um sentir-se reconhecido, autorizar-se, dotar-se de uma autoridade e da autonomia que vai na direção da construção do ser. É promover uma mudança em sua condição, sair da apatia para uma condição de ação - ainda que com atraso!10

Esta mudança carrega em si mesma o poder de emancipar, qual Prometeu acorrentado $^{11}$ que, uma vez liberto do incessante ataque da águia, restitui em si o potencial que o anima. O ser, sendo livre de culpabilidade [do sentir-se incapaz,

\footnotetext{
$10 \mathrm{O}$ atraso a que nos referimos se dá quando o reconhecimento não foi efetivado na infância.

${ }^{11}$ Nas palavras de Hacquard (1996) "Prometeu é o filho do Titã Jápeto e da Oceânide Clímene, é irmão de Epimeteu, Atlas e Menécio. Uma lenda tardia apresenta-o como o criador dos primeiros homens a partir da terra argilosa. Mas a Teogonia de Hesíodo apresenta-o somente como o benfeitor de uma humanidade já criada. No decurso de um sacrifício, Prometeu teria iludido Zeus, em proveito dos homens: o deus, tendo de escolher entre uma parte sedutora, que não reunia mais do que ossos, e uma menos sedutora, mas, que continha a carne, escolheu a primeira, deixando a segunda para os humanos. Furioso por ter sido enganado, Zeus vingou-se, privando os homens do fogo. Mas Prometeu restituiu-lhes o precioso elemento: bastou para isso roubar algumas faíscas à roda do carro solar. Zangado, mais uma vez, Zeus voltou a vingar-se sobre a humanidade, enviando a bela e perversa Pandora a Epimeteu, que fez dela sua mulher. E Pandora derramou sobre os mortais todos os males contidos no vaso de que era portadora. Quanto a Prometeu, Zeus acorrentou-o no cimo do monte Cáucaso, onde uma águia lhe devorava o fígado, que se renovava permanentemente. Héracles, encarregado de ir procurar as maçãs das Hespérides, passou pelo monte e pediu conselho a Prometeu, que tinha o dom da visão, sobre o caminho a seguir. Como forma de agradecimento, libertou-o das suas amarras, matando a águia insaciável com uma flecha" (HACQUARD, 1996, p. 125).
} 


\section{Atos de Pesquisa em Educação - ISSN 1809-0354 \\ Blumenau, v. 13, n.3, p.462-486, set./dez. 2018 \\ DOI: http://dx.doi.org/10.7867/1809-0354.2018v13n3p462-486}

menos que os outros] e estando ciente de seu poder, pode dar-se ao exercício de suas capacidades.

Na esfera pública, é por meio da consideração do outro, no entender suas diferenças, no reconhecer, por meio do mutualismo, que todos somos dignos em igual proporção, que se encontra a possibilidade de reconquista de "si-mesmo". É viver a alteridade onde "[...] soy llamado a vivir-bien con y para otro en instituciones justas [...]" (RICOEUR, 2006a, p. 392).

Para recompor a injustiça sofrida, a solução dar-se-á na figura do respeito. Note-se que o respeito que será dado neste processo não é normativo, não se trata de respeito no sentido da norma formal, antes se faz no outro e com o outro, na reciprocidade, ultrapassando o valor da norma. Está posto no sentido de ver o "simismo como otro" como nos convida Ricoeur (2006a) a compreender - eu respeito o outro [a qualquer um] por respeito a mim mesmo.

\footnotetext{
Que el respeto de sí, que responde en el plano moral a la estima de sí del plano ético, sólo alcanzará su significación [...], cuando el respeto de la norma se haya desplegado en respeto del otro y de "sí mismo como otro", y que éste se haya extendido a cualquiera que tenga derecho a esperar su justa parte en un reparto equitativo (RICOEUR, 2006a, p. 213).
}

Este reconhecimento mútuo, esta conquista, passa pela ontologia, pela ressignificação que encontra sua fundamentação no $\operatorname{ser}^{12}$. Quando esta fenomenologia de si se encontra "perdida", há que ser feito uma espécie de "resgate", que traduzido significa "[...] apostar por uma ontologia que abra el camino apropriado para que la fenomenologia del si alcance su fundamentación en el ser [...]" (BEGUÉ, 2003, p. 315). Ou seja, apostar em ações concretas no aqui e agora, que propiciem um reencontro consigo mesmo, com seu próprio ser e com o mundo.

A necessária redescoberta de "si-mesmo", que se propõe por meio do reconhecimento e da ipseidade, coloca o adulto diante de um mundo repleto de descobertas: [...] "a ipseidad inaugura la dimensión ético-poética de nuestra identidad, donde el reconocimiento mutuo y la creatividad ligada a dicho reconocimiento ocupan una importancia radical [...]" (BEGUÉ, 2003, p. 684).

\footnotetext{
12"Aqui o ser é o ser-no-mundo, o homem corporificado, de ontologia. "Hablamos de manera sensata de la corporeidad y del ser-en-el-mundo porque 'el ser se dice de muchas maneras. Hay una pre comprensión de ello cada vez que adscribimos predicados a esta entidad especial que es la persona" (BEGUÉ, 2003, p. 338, tradução livre).
} 


\section{Atos de Pesquisa em Educação - ISSN 1809-0354 \\ Blumenau, v. 13, n.3, p.462-486, set./dez. 2018 \\ DOI: http://dx.doi.org/10.7867/1809-0354.2018v13n3p462-486}

Ser reconhecido e reconhecer-se como ser de capacidades, para alguém que ao longo da vida passou "despercebido" ou camuflado, que passou como um “Gasparzinho", como conceitua Pérez (2004), é o equivalente à metáfora da Fênix ${ }^{13}$ um renascer das cinzas.

Há que ser reerigida a identidade do sujeito. Por meio desta reconstrução, surge a instauração do homem capaz, produto do reconhecimento mútuo, mediado pelo reconhecimento de "si-mesmo" e da "alteridade"14. Para Ricoeur (2006b, p.202),

[...] trata-se de procurar no desenvolvimento das interações conflituosas a fonte da ampliação paralela das capacidades individuais evocadas no segundo estudo sob o signo do homem capaz em conquista de sua ipseidade $[\ldots]$.

Perscrutar os sinais que emergem das interações sociedade-indivíduo que, embora manifestos, não tenham sido apreendidos, é dar oportunidade de reafirmação do sujeito que age sobre o mundo, do sujeito que, como agente de promessa, narra sua própria história, atribuindo a "si-mesmo" a genealogia de suas ações. Dessa forma, o ato de prometer...

[...] se dá assim ao mesmo tempo como uma nova dimensão da ideia de capacidade e como a recapitulação dos poderes anteriores: teremos a oportunidade de observar que poder prometer pressupõe poder dizer, poder agir sobre o mundo, poder narrar e formar a ideia da unidade narrativa de uma vida, por fim, poder imputar a si mesmo a origem dos próprios atos (RICOEUR, 2006b, p. 139).

Prometer é antes de tudo deixar marcas nas histórias, narrativas ${ }^{15}$ da vida, sinais oriundos de atos feitos por nós mesmos, como agentes. É a capacidade que acompanha o homem de poder dizer, de prometer agir e ao mesmo tempo de

\footnotetext{
13 "A Lenda da Fênix concerne sobre tudo a morte e o renascer da ave. É a única de sua espécie, portanto, não pode se reproduzir como os demais animais. Quando a Fênix sente se aproximar o fim de sua existência, acumula plantas aromáticas, incenso, cardamomo e fabrica com tudo isso uma espécie de ninho. [...] a ave prende fogo a esta oleosa pira e de suas cinzas surge uma nova Fênix" (GRIMAL, 2008, p. 196).

${ }^{14}$ Alteridade pode ser compreendida como "[...] Ser outro, colocar-se ou constituir-se como outro" (ABBAGNANO, 2007, p. 34). Para Ricoeur (2006a) a alteridade é a alteridade do si com outro distinto de si, na qual a "[...] nueva dialéctica de lo Mismo y de lo Otro es suscitada por esta hermenéutica que, de múltiples formas, atestigua que lo Otro no es sólo la contrapartida de lo mismo, sino que pertenece a la constitución íntima de su sentido" (RICOEUR, 2006a, p. 365).

${ }^{15}$ Segundo Castro (2002), o estudo de Ricoeur "[...] sobre a narrativa justifica a nossa convicção de que a imaginação criadora, própria da Crítica da faculdade do juízo e a imaginação produtora, presente na Crítica da razão pura se cruzam para a inteligibilidade do que Ricoeur denomina identidade narrativa" (CASTRO, 2002, p. 21). Menciona duas das três críticas de Kant: há ainda a crítica da razão prática.
} 


\section{Atos de Pesquisa em Educação - ISSN 1809-0354 \\ Blumenau, v. 13, n.3, p.462-486, set./dez. 2018 \\ DOI: http://dx.doi.org/10.7867/1809-0354.2018v13n3p462-486}

concretizar estas promessas, realizando-as. É um dar crédito a "si-mesmo", às suas potencialidades, é um fazer mediante o processo de assinatura de seu poder "[...] sob a rubrica do homem capaz [...]" (RICOEUR, 2006b, p. 139). É "sei lá que" de fé em "si-mesmo", que nos capacita a agir.

Após trancafiar as expectativas e sonhos em um ato de sobrevivência, abandonando, em nome do conforto de sentir-se um igual dentre os iguais, voltar a se encontrar, equivale a redescobrir-se, reconhecer-se e passar pela reconquista do impulso mágico que levará às descobertas de um mundo novo, assinado por meio do vocábulo - "eu posso". Faz-se, portanto, necessária uma retomada da consciência do homus de possibilidades, para tornar-se o homus atuante que, dotado da certeza em "si-mesmo", é a viva expressão do sujeito liberto. Trata-se, pois, de "[...] resgatar una ontologia [...]" (BEGUÉ, 2003, p. 315), do sujeito de atestação.

Nesta conquista entra em cena mais uma vez a imaginação que, em Ricoeur (2002), incorpora ou gera fatores de agregação e rearranjo, que agem tardiamente na etapa adulta, no intuito de novamente "tecer a história de vida". A imaginação nos estudos de Begué (2003) aparece como uma figura de captura do passado, enquanto até aqui vínhamos trabalhando-a como futuro ou antecipação. Em...

Respecto del pasado, la imaginación tiene un rol fundamental en la capacidad de reunir mediante el relato lo diseminado de la experiencia, en la constitución de las intrigas que fundan la historia de una vida o de una comunidad y en la producción de obras que atestiguan las convicciones que cada uno se ha forjado (BEGUÉ, 2003, p. 26).

O fato de se viver a vida não significa que já a compreendemos, é preciso que os diferentes momentos de vida, as recordações evocadas, sejam reorganizados. A imaginação pode reunir as peças, reagrupá-las de modo que a pessoa possa perceber o que realmente é. Para Ricoeur (2002, p. 24) é,

[...] necesario ocuparse del funcionamiento de la imaginación productora y del esquematismo que es su matriz inteligible. En ambos casos la innovación se produce en el medio del lenguaje y revela algo de lo que puede ser una imaginación que produce según reglas [...].

Para este reagrupar peças, o hermeneuta francês faz uso do esquematismo proposto por Kant (2001), deslocando da inovação semântica da linguagem para a reconstrução do "si-mesmo". A partir da narração de "si-mesmo", surge a 


\section{Atos de Pesquisa em Educação - ISSN 1809-0354 \\ Blumenau, v. 13, n.3, p.462-486, set./dez. 2018 \\ DOI: http://dx.doi.org/10.7867/1809-0354.2018v13n3p462-486}

autodesignação e a atestação "sou eu quem" narro e designo a mim mesmo. Este esquema narrativo humano é explicado por Cesar (2002, p.51):

O homem se compreende pela narrativa, pela narração de suas experiências, porque apreende assim os acontecimentos como uma totalidade significativa. [...] A identidade narrativa permite ao indivíduo responder à questão: "Quem sou eu?" (Soi même comme un autre, p. 198). E, deste modo tornar-se reconhecível por suas ações, identificável por seu caráter [...].

São essas diferentes leituras que a pessoa faz de si mesma, e que se abrem em novas perspectivas, as que também "fecham gretas" e "curam feridas", fortalecendo-a e possibilitando ao ser humano reinventar a "si-mesmo". Para Begué (2003, p.340),

[...] es más, en el propio acto de narrar el sí-mismo se eleva al rol de personaje poético de la narración, sea como autor implicado o como elemento de la intriga [...]. Su yo se va entretejiendo con la poética de la puesta en intriga que el relato confiere, y también con las dimensiones éticas, moral y religiosa que su propia interioridad cultiva, las que, junto con la exterioridad de sus actos, producen como resultado su ipseidad.

É a partir desta reunião das peças ou tramas de vida que é possível ao indivíduo começar a agir sem constrangimento, com toda sua força para atuar na reinterpretação de uma vida, no reescrever sua história.

\subsection{EDUCAÇÃO ENTREMEADA PELA IMAGINAÇÃO: PROJETO E REALIZAÇÃO}

Por meio da reunião dos fios da própria vida, em uma releitura autoral, revalorizar o próprio potencial é possível, tornando viável o edificar-se; nesse movimento, certa dose de liberdade está necessariamente envolvida. Sim, porque a imaginação...

[...] se acompaña con la libertad. E este acompañamiento se da en dos niveles: el de liberar al hombre, en lo posible, del reino de la necesidad, y el de incentivar la afirmación y la promoción del sí-mismo [...] (BEGUÉ, 2003, p. 26).

Portanto, é a promoção do homem livre, autoconsciente, do homem cônscio de si, que vai, como um ato em promessa movido por seus próprios impulsos, rumo à concretude da realização. 


\section{Atos de Pesquisa em Educação - ISSN 1809-0354 \\ Blumenau, v. 13, n.3, p.462-486, set./dez. 2018 \\ DOI: http://dx.doi.org/10.7867/1809-0354.2018v13n3p462-486}

Si bien la persona se determina en el acto de voluntad, esta autodeterminación es un acto segundo, un acto de 'recolección' (reprise) de reactivación y reconocimiento de sí, que se apoya sobre un movimiento primero mediante el cual la voluntad posiciona propiamente su acto. Este es el acto propiamente inaugural que abre un 'posible práctico' e instaura reales novedades (BEGUÉ, 2003, p.38).

É nesta construção do ser de promessas que se transforma no ser de realizações, que aparece a "imaginação" vista em dois momentos - como parte do processo criativo que age na edificação do "si-mesmo" e como "recoleção" dos fatos e eventos para recompor a trama da vida.

No primeiro momento a imaginação age como um método antecipatório, como que antecipando uma ação. Se puder ver antecipadamente o desfecho de algo que quero construir, por exemplo, sinto-me incentivada e compelida à ação. É exatamente neste ponto que a imaginação, como antecipação ao ato, consegue incentivar e promover a execução do projeto. Sendo assim, podemos afirmar que é, de fato, a imaginação, uma peça preponderante nos intricados processos do reconhecimento de "si-mesmo", como sujeito capaz de ações. A ação "[...] se le atribuye a la imaginación creadora y al esquematismo en el plano de la práctica social [...]' (RICOEUR, 2002, p. 12).

Também podemos dizer que edificar o futuro pressupõe uma legitimação do presente. Firmar-se como um ser dotado de confiança em si mesmo é, antes de tudo, firmar um entendimento e uma compreensão poética do "si-mesmo, no aqui e agora". Para Begué (2003, p. 686), extraindo de si, traçando reajustes, vendo que,

El lado positivo nos dice que, desde este fondo indeterminado de ignorancia, podemos extraer nuestra capacidad de invención y de superación, para ir más allá de los vaivenes ónticos de nuestra afectividad y tejer una ipseidad más o menos durable, sin demasiadas claudicaciones.

Assim, também, recompor o futuro com base em processos passados é reinventar-se de forma a ajustar a condição humana, aceitando o chamado a participar da construção de mundo. Segundo a autora, é em seu próprio espaço, como ser ontológico, não distante de sua temporalidade, que este se abrir ao mundo, ao "mundo das possibilidades", efetua-se.

Daí a importância de ser "neste" momento histórico, no seu momento histórico, no qual necessitamos garantir "[...] amparo e liberdade [...]" (JESUS, 2013, 


\section{Atos de Pesquisa em Educação - ISSN 1809-0354 \\ Blumenau, v. 13, n.3, p.462-486, set./dez. 2018 \\ DOI: http://dx.doi.org/10.7867/1809-0354.2018v13n3p462-486}

p.50) para que cada qual possa desenvolver-se cognitiva e psiquicamente como um ser de realizações. Assim, se

[...] revela de lleno su concepción antropológica. Que no concibe al hombre fuera de la temporalidad. El tiempo constituye la primera consecuencia de la existencia encarnada, ya que tiene directas y profundas conexiones con el mundo de la vida. Pero también se trata del tiempo que se entrelaza de manera indisoluble con el mundo: tanto con el mundo cultural que manifiesta la historia personal y social [...] (BEGUÉ, 2003, p. 26).

Pareceria que é precisamente no momento histórico vivenciado pela pessoa que é possível ampará-la, favorecendo o seu encontro consigo mesma. Pois é o caráter temporal que a define.

É na autonomia, na liberdade e no reconhecimento com as intrincadas conexões com o mundo, em meio ao mutualismo e à outridade, na livre expressão de suas capacidades, que vamos encontrar o elo que pode conduzir o ser de promessas a um ser de ações concretas.

Dessa forma, o "amparo", a "liberdade" (JESUS, 2013, p. 50) e a imaginação, quando juntas, possibilitam a ação criadora presente em todos os seres como potência; na criança fazem desabrochar as promessas e nos adultos abrem as cadeias do entendimento e dão acesso ao reconhecimento de "si-mesmas". Desta forma, a imaginação pode ser considerada o agente, o mediador que pode conduzir à liberdade e à autonomia.

É nessa busca do possível que entra a promoção e o auxílio por meio da afetividade e da emoção. Jesus (2013) discorre sobre o amparo do professor em relação ao aluno. Podemos falar, a partir de Ricoeur (2006a, 2006b), amparo "por qualquer um", pelo outro. Assim, pode dar-se o "estopim", que poderá se desenvolver e fazer progredir o caminho rumo à autonomia.

O incentivo, permeado pelo amparo, tem a capacidade, enquanto agente do desabrochar das qualidades inerentes ao sujeito reconhecido, de conduzi-lo à liberdade e à felicidade. Como agente motivador por meio da ação de empuxo da vontade, pode abrir a capacidade de auto-organização do "si-mesmo", no intuito de originar algo novo para si e para os outros.

No esquema abaixo elaborado, podemos acompanhar como a imaginação opera para que a pessoa possa se edificar e passar de uma promessa a um ser de concretude na ação. A imaginação permeia os espaços que vão desde a promessa, 


\title{
Atos de Pesquisa em Educação - ISSN 1809-0354 \\ Blumenau, v. 13, n.3, p.462-486, set./dez. 2018 \\ DOI: http://dx.doi.org/10.7867/1809-0354.2018v13n3p462-486
}

passam pelo reconhecimento de "si-mesmo" como "reconhecimento-atestação", conferindo o poder na qualidade do "eu posso". É a imaginação que faz com que sinta que posso fazer, que tenho capacidade.

Figura 1: Tripé do Reconhecimento como promessa e poder

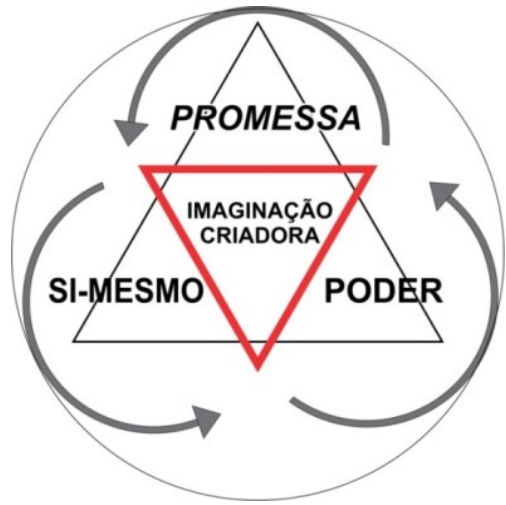

Fonte: Elaborado a partir de Ricoeur (2002, 2006a, 2006b)

No segundo momento, já no adulto, a imaginação tem a potencialidade de prover a abertura dos meios de realização humanos. Em poucas palavras, podemos dizer que a imaginação faz aqui um papel de coletora dos dados da vida, que estão dispersos. Em uma espécie de método que reorganiza os fatos, abre novas possibilidades.

\begin{abstract}
Aquí entra en juego la imaginación productora como esquematización de esta operación sintética de acercamiento. La imaginación es esa competencia, esa capacidad de producir nuevas especies lógicas por asimilación predicativa y producirlas a pesar de - y gracias a - la diferencia inicial entre los términos que se resisten a la asimilación (RICOEUR, 2002, p. 24).
\end{abstract}

Primeiramente, a imaginação age na evocação da epoqué ${ }^{16}$ humana, isto é, promove a retomada da consciência de si, acerca de dados, sintetiza-os, por meio de mudanças em sua própria percepção [de "si-mesmo" e do mundo], instaura uma nova lógica, um novo modo de entender e pensar o mundo. É a retomada dos processos interiores e exteriores ao sujeito, fruto das experiências humanas. Assim se constitui

\footnotetext{
${ }^{16}$ Compreendemos epoché como sendo experiências conscientes, obtidas por meio de mudanças na percepção (do si-mesmo e do mundo). É a tomada de consciência dos processos interiores e exteriores ao sujeito, frutos das experiências humanas. A própria suspensão dos pré-juizos, para que seja revelada a essência das coisas.
} 
Atos de Pesquisa em Educação - ISSN 1809-0354

Blumenau, v. 13, n.3, p.462-486, set./dez. 2018

DOI: http://dx.doi.org/10.7867/1809-0354.2018v13n3p462-486

o sujeito capaz. Desta capacidade advirá a poiésis ${ }^{17}$ do sujeito de ação ou sua própria edificação, o homem passa a narrar a "si-mesmo", a imputar a si seus próprios atos.

Figura 2: Tripé do Reconhecimento - como atestação e poiésis

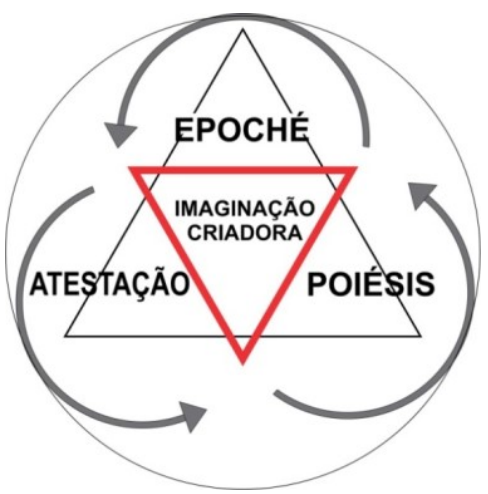

Fonte: Elaborado a partir de Ricoeur (2002, 2006a, 2006b, 2010)

A imaginação, quando aliada aos processos cognitivos, insufla estados de ânimo, automotivação, agrega forças, edifica bases, em um processo longe de finitude, no qual a criatividade aparece em um continuum que não se esgota. É a ação da imaginação aqui apresentada como ponte entre a possibilidade e a concretude, ponte esta que bem pode, ou poderia, ser construída no percurso escolar da criança, adolescente ou, mesmo, no adulto.

\section{ALGUMAS CONSIDERAÇÕES SOBRE O MÉTODO FENOMENOLÓGICO HERMENÊUTICO}

Neste diálogo em busca de compreensão fez-se uso da hermenêutica para o entendimento dos diferentes escritos estudados. Para Ricoeur (1990, p.10), a hermenêutica é "a teoria das operações da compreensão em sua relação com a interpretação dos textos." Para Coltro (2000), estudioso do pensamento de Ricoeur, as interpretações hermenêuticas ligadas à fenomenologia atem-se a desvendar os sentidos perceptíveis e aparentes. Ainda que estes se apresentem nas entrelinhas do

\footnotetext{
17 "POIÉTICO (in: Poietic, fr. Poiétique; ai. Poietik, it. Poietico). Produtivo ou criativo" (ABBAGNANO, 2007, p. 772). Para Begué (2003) "Poiesis es el acto configurador, la operación de componer los hechos o las afecciones en un sistema. La acción poética canaliza y transmite aquellas experiencias que testimonian esas múltiples dimensiones. Ella lo hace abriendo nuevos espacios" (BEGUÉ, 2003, p. 151).
} 


\section{Atos de Pesquisa em Educação - ISSN 1809-0354 \\ Blumenau, v. 13, n.3, p.462-486, set./dez. 2018 \\ DOI: http://dx.doi.org/10.7867/1809-0354.2018v13n3p462-486}

que não foi dito ou percebido ou se encontrem sob o signo da ocultação, situando-se no que o fenômeno tem de mais fundamental, nos significados, refletindo-se por meio da descrição e interpretação. Vejamos o detalhamento explicado, neste caso, por Fazenda (2000), em dois passos: a descrição e a interpretação.

1 - Descrição é considerada em Fenomenologia um caminho de aproximação
do que se dá, da maneira que se dá e tal como se dá. Refere-se ao que é
percebido do que se mostra (ou do fenômeno). Não se limita à enumeração
dos fenômenos como o positivismo, mas pressupõe alcançar a essência do
fenômeno. 2 - Interpretação - "trabalho do pensamento que consiste em
decifrar o sentido aparente, em desdobrar os sinais de significação implicados
na significação literal... há interpretação onde houver sentido múltiplo e é na
interpretação que a pluralidade de sentidos torna-se manifesta". (FAZENDA,
2000, p. 63).

Trata-se, pois, do desvelar o essencial do fenômeno e, como afirma Japiassu (1990, p.18), "[...] de uma decodificação hermenêutica do universo dos signos [...]". Trata-se de compreender por meio da hermenêutica as possíveis relações que o fenômeno regional ${ }^{18}$ tem com os textos interpretados, para assim tornar-se mais global $^{19}$. Fenômenos que, segundo Ricoeur (1990, p.18), "[...] devem estar subordinados a preocupações ontológicas."; para o sujeito, "[...] compreender deixa de aparecer como um simples modo de conhecer, para tornar-se uma maneira de ser e de relacionar-se com os seres e com o ser" (RICOEUR, 1990, p. 27), englobando a presença do homem no mundo.

A problemática inerente ao fenômeno é esmiuçada em sua essência; deve-se percebê-la para posteriormente levá-la à compreensão, "[...] pela redescoberta de seu princípio ontológico ${ }^{20}$ [...]" (RICOEUR, 1990, p. 4), mediante o pressuposto que já estava ali, enquanto manifestação intrínseca da ontologia de ser no mundo. Pois, para ele, a fenomenologia lida com a tentativa de convergência dos discursos humanos.

\footnotetext{
18 Não global.

${ }^{19}$ Neste contexto, que propicie um entendimento que pode ser generalizado, enquanto ontologia que envolve trocas advindas do relacionamento mútuo.

20 "'Óntico' puede traducirse: 'que se refiere a los entes' [...]. Ontológico' puede traducirse: 'que se refiere al ser'. Según Heidegger (Cfr. Sein und Zeit, sobre todo $\S \S 3,4,10,77)$, 'la descripción del ente intramundano (des innerweltlichen Seienden) es óntica; la interpretación del ser de este ente (des seins diesen Seienden) es ontológica" (FERRATER MORA, 1964, p. 320).

Segundo Castro (2002) "Ontológico, na medida em que Ricoeur o que pergunta é pelo Ser. Pelo ser desse Eu que pensa, que conhece, que age, que sente, numa palavra, que vive e vai sendo" [...] (CASTRO, 2002, p. 15).
} 
Pode-se, portanto, por meio da investigação, transpor a aparência dos elementos adjacentes ao fenômeno, podendo-se conceituar que a essência da pesquisa é a compreensão do sentido do inacabamento da existência humana. E é nessa complexa existencialidade que o ser, como ente ontológico, busca por meio da autonomia e do autodidatismo, a realização do humano.

\section{CONSIDERAÇÕES FINAIS}

A partir das considerações sobre o conceito de imaginação, criatividade e reconhecimento pudemos compreender que somos capazes, que podemos ser ativos, como agentes que modificam o próprio entorno. Se a temática em questão gira em torno da promoção da posição autodidata, por meio do reconhecimento e do autorreconhecimento de "si" como capaz de ação, cumpre-nos agora extrair algumas implicações para a educação.

Em primeiro lugar, faz-se necessário oportunizar possibilidades para que o sujeito cresça e compreenda por si mesmo que é possível desabrochar; que cada um de nós pode se transformar em um sujeito que age, em um sujeito de ação. E é nesta "promoção" que reside a importância primeira da escola, em seu papel de favorecer o desenvolvimento destas capacidades inerentes ao ser humano.

A escola e os educadores podem ser o amparo que auxilia nos momentos de descoberta, do desabrochar para o mundo. Pode a escola não somente ensinar, transmitir conteúdos e incrementar cognitivamente os estudantes, mas também proporcionar espaço de liberdade para a criação.

Seria preciso que os estudantes compreendessem que, somente por meio da ética e da moral, levando em consideração não somente o "eu", mas, ocupando-se de outrem como se ocupa de "si-mesmo", é possível a convivência edificante. Levá-los a compreender a reflexividade de suas ações; ações que se pautem na busca de diálogos mediados pelo respeito e pela consideração.

Para Jesus (2013), é um dever da escola instigar a busca de novos desafios que contemplem os processos cognitivos e o emprego coerente do conhecimento. Mas, acima de tudo, é necessário que tenhamos a compreensão de que é preciso um 
Atos de Pesquisa em Educação - ISSN 1809-0354

Blumenau, v. 13, n.3, p.462-486, set./dez. 2018

DOI: http://dx.doi.org/10.7867/1809-0354.2018v13n3p462-486

contexto de liberdade para os educandos se desenvolverem, sendo amparados diante das dificuldades. E que esta liberdade está acompanhada da autonomia, da autolegislação.

A mão que ampara é antes de tudo um "porto seguro" que encontramos nos instantes de ultrapassar os limites da segurança, na busca do novo. Liberdade para sermos nós mesmos, cada um com suas potencialidades, suas debilidades e desafios. Enfim, ao congregar em um mesmo ambiente, a segurança e a liberdade dispostas em conjunto, uma mescla de imaginação, confiança e aprendizado poderá oferecer ao sujeito a riqueza de descobrir, por si próprio, de forma autônoma, como buscar os meios para a transformação de seu entorno, participando do mundo ativamente.

É nesse contexto que os locais de ensino e a sociedade têm a missão de buscar os meios de prover o incremento das capacidades e atributos inerentes ao indivíduo, meios que valorizam o humano e contribuem para a construção do ser, transformando-o, capacitando-o.

Pois, é mediante a compreensão de seu papel no mundo que, também, adultos, até então pouco ativos ou inertes em decorrência do não reconhecimento e da falta de fé em "si", podem transformar-se e crescer; é um permitir a "si-mesmo" o reencontro com um novo estado de ânimo.

\section{KAREENN CRISTINA ZANELA DIENER}

Mestre em Educação pela Universidade do Planalto Catarinense - UNIPLAC. Docente na Universidade do Planalto Catarinense (UNIPLAC), nos cursos de Design, Artes Visuais e Arquitetura e Urbanismo.

\section{ANA MARIA NETTO MACHADO}

Doutora em Ciências da Linguagem (Université Paris X, Nanterre) e em Educação (revalidação, UFRGS, 2004).

\section{REFERÊNCIAS}

ABBAGNANO, N. Dicionário de filosofia. Tradução Alfredo Bosi. São Paulo: Martins Fontes, 2007, $1232 \mathrm{p}$.

BEGUÉ, M. Paul Ricoeur: la poética del sí-mismo. Buenos Aires: Biblios, 2003, 278 p. 
Atos de Pesquisa em Educação - ISSN 1809-0354

Blumenau, v. 13, n.3, p.462-486, set./dez. 2018

DOI: http://dx.doi.org/10.7867/1809-0354.2018v13n3p462-486

CASTRO, M. G. A. e. Imaginação em Paul Ricoeur. Lisboa: Instituto Piaget, 2002, $321 \mathrm{p}$.

CESAR, C. M. A ontologia hermenêutica de Paul Ricoeur. In: (org). $A$ hermenêutica francesa: Paul Ricoeur. Porto Alegre: EDIPUCRS, 2002, p. 43-55.

COLTRO, A. A fenomenologia: um enfoque metodológico para além da modernidade. Cadernos Pesquisas em Administração, São Paulo, v. 1, n. 11, p. 3745, jan./abr. 2000. Disponível em: <http://www.ead.fea.usp.br/cadpesq/arquivos/c11-art05.pdf>. Acesso em: 20 jul. 2016.

FAZENDA, I. (Org). Metodologia da Pesquisa Educacional. São Paulo: Cortez, 2000, $175 \mathrm{p}$.

FERRATER MORA, J. Diccionario de Filosofía. Tomo I e II. Buenos Aires: Editorial Sudamericana, 1964, $2017 \mathrm{p}$.

GRIMAL, P. Diccionario de Mitologia Griega y Romana. Barcelona: Paidós, 2008, 672 p.

HACQUARD, G. Dicionário de Mitologia Grega e Romana. Tradução Maria Helena T. Lopes. Rio Tinto: ASA, 1996, 320 p.

JAPIASSU, H. Prefácio. In: RICOUER, P. Interpretação e Ideologias. Rio de Janeiro: Francisco Alves, 1990, 174 p.

JESUS, P. C. S. G. de. Escrever na educação superior: caminhos para autoria na universidade. 2013. 92 p. Dissertação (Mestrado). Programa de Pós-graduação em Educação da Universidade do Planalto Catarinense. Lages, Santa Catarina.

KANT, I. Sobre a pedagogia. Tradução Francisco Cock Fontanella. Piracicaba: EDUNIMEP, 1996, $107 \mathrm{p}$.

Crítica da Razão Pura. Tradução Manuela Pinto dos Santos e Alexandre

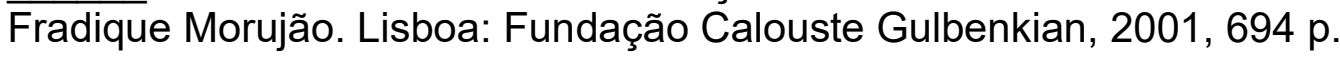

LANDAU, E. A coragem de ser superdotado. Tradução Sandra Miessa. São Paulo: Arte e Ciência, 2002, 224 p.

Creatividad: el camino holístico a la superdotación, 1996. Disponível em: <http://www.juanserranocazorla.com/textos-sobre-altas-capacidades/>. Acesso em: 11 fev. 2014.

PÉREZ S. G. Gasparzinho vai à escola: um estudo sobre as características do aluno com altas habilidades produtivo-criativo, 2004. Disponível em: < http://www.bdae.org.br_dspace_bitstream_123456789_898_1_tese>. Acesso em: 02 ago. 2016. 
RAYNOVA, I. Paul Ricoeur. Instutut fur Axiologische. Disponível em: <http://ricoeur.iaf.ac.at/FR/index.htm>. Acesso em: 09 set. 2014.

RENZULLI, J. The three-ring conception of giftedness: a developmental model for creative productivity. In: Sternberg, R.; Davidson, J. (Eds.), Conceptions of giftedness. 2. ed. New York: Cambridge University Press, 1986. p. 258-291.

RICOEUR, P. Interpretação e ideologias. Organização, tradução e apresentação de Hilton Japiassu. Rio de Janeiro: Francisco Alves, 1990, 174 p.

. Del texto a la acción: ensayos de hermenéutica II. México: Fundo de Cultura Económica, 2002, 388 p.

Sí mismo como otro. México: Siglo XXI, 2006a, 125 p.

. Percurso do reconhecimento. Tradução Nicolás Nyimi Campanário. São Paulo: Loyola, 2006b, 280 p.

A luta por reconhecimento e a economia do dom. Tradução Cláudio Reichert do Nascimento e Noeli Dutra Rossatto. Ethic@ - Revista Internacional de Filosofia da Moral, Florianópolis, v. 9, n. 2, p. 357-367, dez. 2010.

Ricoeur Studies - Revista eletrônica. Capa, v. 4, n. 2, 2013. Disponível em: <http://ricoeur.pitt.edu/ojs/index.php/ricoeur/article/view/87>. Acesso em: 9 jul. 2016.

SENNETT, R. Autoridade. Tradução Vera Ribeiro. Rio de Janeiro: Record, 2001, 272 p.

STERNBERG, R. The Nature of Creativity. Creativity Research Journal. Lawrence Erlbaum Associates, Inc. v. 18, n. 1, 2006, p. 87-98. Disponível em: $<$ http://people.uncw.edu/caropresoe/giftedfoundations/SocialEmotional/Creativityarticles/Sternberg_Nature-of-creativity.pdf> Acesso em: 15 set. 2016. 